\title{
What inspires us to "share"? Motives to provide goods and services in the sharing economy
}

\author{
Patricia Quirós \\ Jacobs University Bremen, Germany \\ quirospv@gmail.com
}

\begin{abstract}
The sharing economy allows individuals to provide goods or services on sharing platforms, but little is known about what motivates people to share or provide in these platforms. This study aims to analyze what inspires people to participate in the sharing economy as providers of goods and services. A framework with five determinants for willingness to provide (monetary compensation, flexibility, trust, convenience, and sense of belonging) is developed and tested using Partial Least Squares Structural Equation Modeling on data gathered in an online survey. The results show that sense of belonging has a significant positive effect on willingness to provide goods and services. Surprisingly, monetary compensation has a significant negative effect on willingness to provide goods. Having the same values, culture and common interests proves to be the main motive to share with strangers instead of earning money as previously believed.
\end{abstract}

\section{Introduction}

The sharing economy (SE) is a system where idle assets or services are offered to others [9]. Pioneers in different sectors of the sharing economy such as Uber and Airbnb have successfully disrupted industries believed to be stable, the taxi and the hospitality industries respectively. While the sharing economy is growing in popularity [6], there is still a lack of research on it [13]. Besides focusing on the advantages and disadvantages that the sharing economy brings and how it can be used as a new source of income for its users, studies have focused on isolated determinants (e.g. service quality, internet capability, utility and cost savings) [34], demographics (e.g. gender, age and race) of users [26], and consumer segmentation of users [33]. Furthermore, previous research [27], [30], [34], has been done on users' behavior in the sharing economy as well as their intentions to participate.

Crucial components for participating in the sharing economy (i.e. trust, utility and user experience) and how the use of digital marketing channels (e.g. email, social media and search engines) contributed to the growth of the organizations have been previously explored [27].

\author{
Stanislav Chankov \\ Jacobs University Bremen, Germany \\ s.chankov@jacobs-university.de
}

Furthermore, the determinants of satisfaction of using a sharing economy platform and what determined the likelihood of choosing a sharing option again have also been considered [34]. Likewise, research has been done on the significant predictors for someone's willingness and intention to participate, specifically in Uber [30].

Nevertheless, while these studies researched the people using a sharing economy platform as a client (referred as "users" hereafter), the determinants of what motivates people to be suppliers of goods or services on sharing economy platforms (referred as "providers" hereafter) have not been explored as much [17]. It remains unclear if the underlying motivations of users and providers are related. While users join the sharing economy as they need access to certain assets or services, providers join the sharing economy as they look for a better use of their idle assets or their time. Still, sharing economy platforms need to increase the number of both their users and providers to remain competitive [7], [29], [38]. There is little available information that allow companies and the academic community to understand why people are willing to provide, or "share", with strangers and how these motives can be leveraged by the platforms [17].

Few studies have explored the activity of providers. [32] analyzed the comprehension of the potential challenges and disadvantages that are associated with being a service provider in the sharing economy. By using semi-structured interviews, [39] identified drivers for participation such as monetary compensation and flexibility regarding task selection and time schedules. [26] later explored, with Airbnb in the United States as a case study, "who joins and who benefits" in a sharing economy. Additionally, [8] studied the motives of both users and providers to participate according to the categories in the first version of the Collaborative Economy Honeycomb [36], used as dimensions. Yet, no study covers a full comprehensive understanding of what inspires providers to share goods or services.

Further examination of the different determinants behind the participation of providers in the sharing economy, and verifying how significant they are, is important for both practice and theory. This investigation will help fill a research gap in literature by analyzing the providers' preferences and what 
influences their willingness to participate in providing goods or services. Moreover, this information may be used by sharing economy companies and platforms in order to target providers, enhance customer experience and develop their business strategies and models.

Thus, the purpose of this paper is to analyze what inspires people to participate in the sharing economy as providers for goods and services. Accordingly, we first develop a framework on the determinants of willingness to provide goods and services in the sharing economy. Second, we conduct an online survey (sample size 205) and Partial Least Squares Structural Equation Modeling (PLS-SEM) to test the framework.

The paper is organised as follows. Section 2 presents the literature review. The hypotheses development is described in section 3 and the research design in section 4. The findings are presented in section 5 and discussed in section 6. Finally, section 7 concludes the paper.

\section{Literature Review}

\subsection{Motives behind using SE platforms}

When selecting different options, as part of the key aspects of ridesharing systems, people consider: reliability, convenience, cost, flexibility, time and perception of security [16]. Meanwhile, looking into the determinants of satisfaction of users of the sharing economy, [34] analyzed the effects of ten factors: community belonging, cost savings, environmental impact, familiarity, internet capability, service quality, smartphone capability, trend affinity, trust, and utility. Four of these (i.e., environmental impact, internet capability, smartphone capability, and trend affinity) were found to have no significant impact. This is especially interesting given other arguments, such as that one salient concern in consumer decision-making choices was that of the environment [2].

[34] found that users are driven by rationality and try to serve their own self-benefit when using the services offered by the sharing economy. Hereby, four significant determinants (utility, familiarity, cost savings and trust) seemed to affect the user enough to choose a collaborative consumption option instead of a non-sharing one [34]. Another interesting perspective is that people become users because it gives them a sense of belonging. Through participation, a sense of community arises and may be considered as the key driver for participation [1]. Finding a community where people share, even for a fee, services or objects gives an illusion of connection to other caring people.

\subsection{Motives behind providing in SE platforms}

In a triadic framework for sharing economy, three main motives are suggested for providers to join the sharing economy: (1) economic benefits, (2) entrepreneurial freedom and (3) social motives [7]. Providers first want to earn extra money by making use of their assets, second they want to offer their assets when and how they want and third they want to meet other people (SE users) who share similar desires.

Further, education and income were found to be the two most influential factors for joining an SE platform as a provider [26]. These two factors refer to providers' initial contact with the platform and do not explain what motivates providers to keep offering their goods and services in the SE platforms on a continuous basis.

As for the main drivers for participation, other studies have pinpointed different options where the drivers that are the most frequently repeated are income, or monetary compensation, and the flexibility to control tasks and schedules [2], [12], [16], [26], [32], [39]. Platforms give providers the opportunity to generate new sources of income as they can choose the renting price of their services and goods as well as control the income they get from them [26]. Besides, platforms only ask for a small fee of the price, so it is perceived that the providers are at an advantage. Further, based on conducted interviews with providers, [39] also point out that monetary compensation is one, if not the only, of the main motivations to become a participant. This determinant for participation also seems to be strongly linked to another motive, flexibility, in the context of Uber drivers where drivers benefit from real-time flexibility by earning more than they would with arrangements with less flexibility [12].

\subsection{Goods versus services}

Goods are defined as tangible and scarce items and, thus, it is logical that goods can be shared between people. Production and consumption can be separated for goods and they are also inherently corporeal. On the other hand, services are intangible and production and consumption are inseparable, i.e. a person consumes a service as it is being produced [25]. Contrary to goods, services, cannot be inventoried and thus have a high 'perishability' [25]. As services are highly perishable and are consumed as they are produced, providers have to physically do the task and sometimes be present when and where the user demands.

Literature so far only covers analyses of case studies or industry-specific examples; however, no study has compared the determinants for sharing goods to those for sharing services. SE offerings are even sometimes considered as only "services" [17], which is imprecise as the nature of goods and services is different. Thus, there is a research gap that needs to be addressed as the motives inspiring people to provide goods and services 
might differ. Due to the differences mentioned above, goods and services are analyzed separately in this paper.

\section{Hypothesis and framework development}

The Self-Determination Theory (SDT) is often used in the sharing economy [21]. SDT suggests that people's motivations are either intrinsic (e.g. enjoyment) or extrinsic (e.g. monetary gain) [43]. Applying the SDT to the willingness to provide goods and services and considering the incentives previously mentioned in the past studies, five determinants were selected: monetary compensation and sense of belonging as extrinsic, and flexibility, trust and convenience as intrinsic. It should be pointed out that only two out of these five determinants (i.e., flexibility and monetary compensation) have been studied in regard to the participation of providers by more than one author, the other determinants have been mentioned mostly in relationship to users of the sharing economy. For each of the five determinants two hypotheses are developed: (a) willingness to provide goods and (b) willingness to provide services, since we aim to analyze the goods and services separately as explained in the previous chapter.

The first two determinants that will be described (e.g. monetary compensation and flexibility) have been already analyzed in the context of providers. The first one, monetary compensation, is the one that has been looked into the most as an extrinsic incentive for providers of the sharing economy It has been looked into as the sole motivation to become a participant as it offers a new source of income [26] and the main driver of participation [39]. Economic motivations are also one of the key dimensions part of the theory of sharing developed by [5] and one of the suggested motives for participating mentioned by [7]. Finally, [18] show that masculinism has a positive effect on providers' willingness to rent out products and masculinists are driven by economic motivations. Thus, the hypotheses related to monetary compensation are:

$\mathrm{H}_{1 \mathrm{a}}$ : Monetary compensation has a positive effect on willingness to provide goods.

$\mathrm{H}_{1 \mathrm{~b}}$ : Monetary compensation has a positive effect on willingness to provide services.

The second determinant is flexibility. [7] explain that sharing economy platforms give providers entrepreneurial freedom (flexible offering and individualization of service). Providers have the flexible ability to choose when and how to provide goods or services, making flexibility an intrinsic motive for providers as it offers them autonomy. Flexibility has only been studied in regard to ridesharing so far, and not in other sectors of the sharing economy. [16] emphasizes the importance of a high level of flexibility in ridesharing. In order to generalize flexibility as a determinant for participation besides ridesharing, the second set of hypotheses is derived:

$\mathrm{H}_{2 \mathrm{a}}$ : Flexibility has a positive effect on willingness to provide goods.

$\mathrm{H}_{2 b}$ : Flexibility has a positive effect on willingness to provide services.

The rest of the determinants are those that are derived based on the literature on users. Starting with the one that has been the most supported: trust [2], [8], [16], [27], [30], [32], [34], [40]. Besides, [32] has also studied trust in the context of providers. Moreover, [17] found out that trust leads to higher job outcome status and job satisfaction for gig workers in the sharing economy, making it an intrinsic motive. Further, [18] show that uncertainty avoidance has a negative effect on providers' willingness to rent out products. When providers participate in the sharing economy, there is always some uncertainty. However, if the providers trust the sharing economy platform, they will be feeling less uncertain. This leads to the third set of hypotheses:

$\mathrm{H}_{3 \mathrm{a}}$ : Trust has a positive effect on willingness to provide goods.

$\mathrm{H}_{3 \mathrm{~b}}$ : Trust has a positive effect on willingness to provide services.

In two of the studies previously mentioned [16], [34] it was found that convenience plays an important role in ridesharing (e.g., pick-up and drop-off points). Some of the authors that talk about convenience, such as [27] and [34] refer to this term as "utility", and both agree that it is crucial for participation and that it affects satisfaction. From the providers' point of view, [39] mention how "convenient physical locations" stood out in most of the interviews performed. Thus, convenience can lead to higher enjoyment for providers making it an intrinsic motive. The fourth set of hypotheses becomes:

$\mathrm{H}_{4 \mathrm{a}}$ : Convenience has a positive effect on willingness to provide goods.

$\mathrm{H}_{4 \mathrm{~b}}$ : Convenience has a positive effect on willingness to provide services.

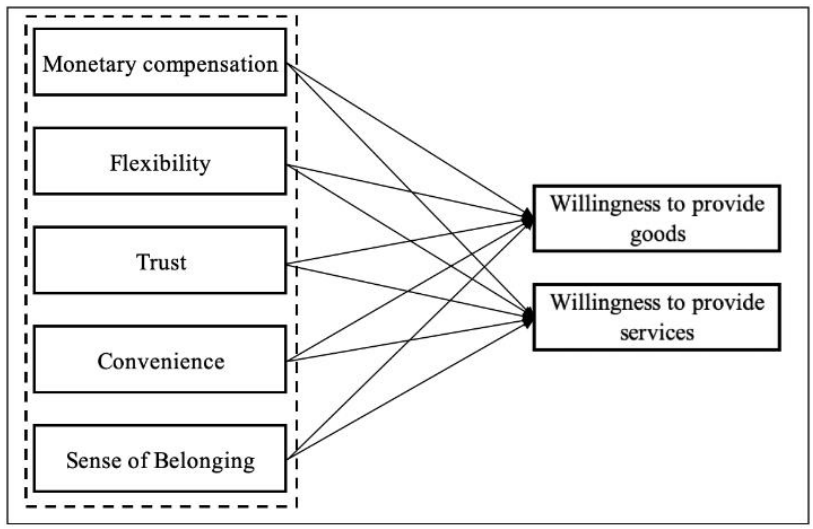

Figure 1. Willingness to Provide Goods and Services in the Sharing Economy Framework 
Table 1: Survey Statements

\begin{tabular}{|c|c|}
\hline Determinant & Statements \\
\hline \multirow{3}{*}{$\begin{array}{c}\text { Monetary } \\
\text { compensation } \\
\text { [self-developed } \\
\text { based on [39]] }\end{array}$} & I earn money. \\
\hline & I obtain a reasonable compensation for my goods/services, time and effort. \\
\hline & My profit exceeds the costs I incur (e.g. service fee). \\
\hline \multirow{3}{*}{$\begin{array}{l}\text { Flexibility } \\
\text { [12] }\end{array}$} & It is simple for me to change the availability of my goods/services. \\
\hline & I should be able to accept or deny someone's offer. \\
\hline & I can change when and for how long I offer my goods/services. \\
\hline \multirow{3}{*}{$\begin{array}{c}\text { Trust } \\
\text { [32], [34] }\end{array}$} & $\begin{array}{l}\text { I am comfortable with providing goods/services because the platform ensures a robust and safe } \\
\text { environment. }\end{array}$ \\
\hline & The platform will protect me from liability and interests of others that do not match with mine. \\
\hline & I trust that the platform shows me accurate updates and information. \\
\hline \multirow{3}{*}{$\begin{array}{l}\text { Convenience } \\
\text { [self-developed] }\end{array}$} & The platform makes it easy to complete a transaction. \\
\hline & The platform offers quick and easy access to the information I need. \\
\hline & The platform is easy to use and self-explanatory. \\
\hline \multirow{3}{*}{$\begin{array}{l}\text { Sense of } \\
\text { Belonging } \\
{[2],[34]}\end{array}$} & I want to feel part of a bigger community of like-minded people. \\
\hline & The use of the platform allows me to belong to a group of people with similar interests. \\
\hline & The platform reflects my culture, values and interests. \\
\hline \multirow[t]{2}{*}{$\begin{array}{l}\text { Willingness to } \\
\text { provide } \\
\text { [self-developed] }\end{array}$} & $\begin{array}{l}\text { I am interested in providing sharing economy services (e.g. driving my car for Uber, taking care of } \\
\text { someone else's pet while they're away in DogVacay, offering my services and skills in TaskRabbit). } \\
\text { I am interested in providing sharing economy goods (e.g. sharing your house in Airbnb, renting your } \\
\text { bike in Spinlister). }\end{array}$ \\
\hline & I prefer to share my idle goods again instead of having them unused. \\
\hline
\end{tabular}

[34] found that community belonging has a positive impact on the likelihood of using a sharing option again. Also, [1] point out that a sense of community is a driver of participation. Their findings show that there is a wish to foster individual and group well-being which begets the emergent theme of community building. The building of interpersonal connections through a sense of belonging then seems to be a recurrent theme in consumers of sharing platforms. The extrinsic benefits that come from a sense of community for users could also relate to providers. [7] suggest that social motives also encourage providers to join the sharing economy as they want to meet people with similar interests. Moreover, [18] find out that collectivism has a positive effect on willingness to rent out products and collectivists have a strong sense of community. Thus, the following hypotheses were developed:

$\mathrm{H}_{5 \mathrm{a}}$ : Sense of belonging has a positive effect on willingness to provide goods.

$\mathrm{H}_{5 \mathrm{~b}}$ : Sense of belonging has a positive effect on willingness to provide services.

From the determinants selected and already explained, a framework on willingness to provide goods and services was developed (see Figure 1).

\section{Methodology}

\subsection{Survey design}

All statements used in the survey are shown on Table 1. For each of the five determinants three statements were created (some adopted from previous literature and some developed by the researchers). Further, we developed two statements for the variable "willingness to provide products" and only one for the "willingness to provide services" in order to avoid repetition. The wording of the self-developed statements were reviewed by independent sharing economy providers to ensure that they are clear and free of bias.

An online survey was chosen due to its ability to reach more participants and its convenience regarding automated data collection. Online surveys are also more time and cost efficient [41]. A six-point Likert scale questionnaire was adopted. This even numbered scale helps minimize the selection of the "uncertain" or "neutral" category that is common in odd numbered point scales [10]. The survey was shared through social media platforms and a university emailing list. The survey was available for a period of 23 days and 205 participants took part in it on a voluntary basis. 
Table 2. Sample Description

\begin{tabular}{|c|c|c|c|}
\hline \multicolumn{2}{|c|}{$\begin{array}{l}\text { Sharing Economy } \\
\text { Experience }\end{array}$} & \multicolumn{2}{|l|}{ Gender } \\
\hline Providers & 38 & Male & 106 \\
\hline Users & 175 & Female & 99 \\
\hline Both & 36 & Other & 0 \\
\hline None & 32 & Prefer not to say & 0 \\
\hline \multicolumn{2}{|c|}{ Age Groups } & \multicolumn{2}{|c|}{ Income Groups } \\
\hline 17 or younger & 1 & 0-300 EUR & 72 \\
\hline $18-24$ y/o & 164 & 301-600 EUR & 56 \\
\hline $25-34$ y/o & 35 & 601-900 EUR & 24 \\
\hline $35-44$ y/o & 2 & 901-1200 EUR & 18 \\
\hline $45-54$ y/o & 2 & 1201-1500 EUR & 14 \\
\hline $55-64$ y/o & 1 & $>1500$ EUR & 21 \\
\hline \multicolumn{2}{|c|}{ Country of Origin } & \multicolumn{2}{|c|}{ Country of Residence } \\
\hline Africa & 14 & Africa & 1 \\
\hline Asia & 66 & Asia & 10 \\
\hline Central America & 8 & Central America & 1 \\
\hline Europe & 73 & Europe & 172 \\
\hline North America & 38 & North America & 20 \\
\hline Oceania & 1 & Oceania & 1 \\
\hline South America & 5 & South America & 0 \\
\hline \multicolumn{2}{|c|}{ Providers (Platforms) } & \multicolumn{2}{|c|}{ Users (Platforms) } \\
\hline Airbnb & 30 & Airbnb & 16 \\
\hline Bla Bla Car & 13 & Bla Bla Car & 9 \\
\hline Car2Go & 6 & Car2Go & 0 \\
\hline Lyft & 3 & Lyft & 0 \\
\hline Uber & 22 & Uber & 6 \\
\hline Other & 12 & Other & 13 \\
\hline
\end{tabular}

\subsection{Sample description}

Table 2 shows the sample description. Out of the 205 participants that completed the survey only 32 have never participated in the sharing economy before, neither as a provider nor as a user (see Table 2). There were 38 participants who have already provided their goods or services in a sharing economy platform where Airbnb was the most popular platform with 30 out of 38 providers providing there, followed by Uber, with 22 (see Table 2). Only two of the providers have never participated as a user before.

$80 \%$ of the participants belonged to the age group of 18 to 24 years of age and the majority of the participants (35\%) had an income between 0 and 300 euros. $83.9 \%$ of participants resided in Europe at the time of the survey. Most of the participants came from Europe (35.6\%), while $32.3 \%$ came from Asia and $18.5 \%$ from North America. Moreover, in total more than 50 countries were represented meaning that the sample covers diverse cultural perspectives.

It can be inferred that most participants are students in European countries. Thus, the sample is not fully representable. However, the sharing economy is predominantly driven by people between 18 and 34 years of age [42] so the sample is still relevant for the sharing economy and can be used to derive conclusions.

\subsection{PLS-SEM methodology}

Partial Least Squares Structural Equation Modeling (PLS-SEM) is an evolving statistical modeling technique which helps measure unobservable variables indirectly by indicator variables [20]. As this study seeks to develop theories, it needs to allow for exploratory research and not to confirm or reject previous ones, PLS-SEM is preferred over covariancebased SEM (CB-SEM). PLS-SEM was also chosen as it is adequate for causal modeling [22].

For the construct reliability and validity, the composite reliability (CR) and the average variance extracted (AVE) were measured for each of the latent variables. $\mathrm{CR}$ measures the internal consistency of the indicators with respect to their latent variable and it is preferred over its equivalent Cronbach's $\alpha$ as the latter tends to underestimate the internal consistency reliability in PLS path models [22]. A CR value above 0.7 is seen as satisfactory in early stages of research and a value over 0.8 and 0.9 in more advanced stages [22]. The AVE score shows convergent validity and that a set of indicators represent the same construct [22]. An AVE value greater than 0.5 is recommended [4], [22].

Table 3 reports the model fit scores. Chi-Square "is the traditional measure for evaluating overall model fit" [23]. The standardized root mean square residual (SRMR) value shows the "square root of the difference between the residuals of the sample covariance matrix and the hypothesized covariance model" [23]. A value lower than 0.08 is seen as acceptable [23]. $R^{2}$ is the " "percent of variance explained' by the model" [35] and a value over 0.10 is recommended [15]. It is important

Table 3. Model fit

\begin{tabular}{lcc}
\hline Determinant & Goods Model & Services Model \\
\hline Chi-Squared & $559.874^{* * *}$ & $454.322^{\star * *}$ \\
SRMR & 0.089 & 0.089 \\
$\mathrm{R}^{2}$ & $0.109^{\star}$ & $0.079^{\star}$ \\
$\mathrm{Q}^{2}$ & 0.046 & 0.028 \\
\hline
\end{tabular}

$* \mathrm{p}<0.05, * * \mathrm{p}<0.10, * * * \mathrm{p}<0.001$ 
Table 4. Construct Reliability and Validity Criteria

\begin{tabular}{|c|c|c|c|c|c|c|c|c|c|c|}
\hline \multirow[b]{2}{*}{ Determinants and Statements } & \multicolumn{5}{|c|}{ Goods } & \multicolumn{5}{|c|}{ Services } \\
\hline & $\begin{array}{l}\text { Outer } \\
\text { Loadings }\end{array}$ & $\begin{array}{l}\text { Mean } \\
(\mathrm{SD})\end{array}$ & $\mathrm{CR}$ & AVE & $\mathrm{Q}^{2}$ & $\begin{array}{l}\text { Outer } \\
\text { Loadings }\end{array}$ & $\begin{array}{l}\text { Mean } \\
(\mathrm{SD})\end{array}$ & CR & AVE & $Q^{2}$ \\
\hline Monetary Compensation & & $\begin{array}{c}5.20 \\
(1.08)\end{array}$ & 0.85 & 0.66 & 0.31 & & $\begin{array}{c}5.20 \\
(1.08)\end{array}$ & 0.86 & 0.67 & 0.3 \\
\hline I earn money. & 0.66 & $\begin{array}{c}5.09 \\
(1.25)\end{array}$ & & & & $0.80^{* *}$ & $\begin{array}{c}5.09 \\
(1.25)\end{array}$ & & & \\
\hline $\begin{array}{l}\text { I obtain a reasonable compensation for } \\
\text { my services/goods, time and effort. }\end{array}$ & $0.80^{*}$ & $\begin{array}{l}5.28 \\
(0.91)\end{array}$ & & & & $0.96^{*}$ & $\begin{array}{l}5.28 \\
(0.91)\end{array}$ & & & \\
\hline $\begin{array}{l}\text { My profits exceeds the costs I incure } \\
\text { (e.g. service fee). }\end{array}$ & $0.95^{\star *}$ & $\begin{array}{c}5.23 \\
(1.08)\end{array}$ & & & & $0.67^{\star \star}$ & $\begin{array}{c}5.23 \\
(1.08)\end{array}$ & & & \\
\hline Flexibility & & $\begin{array}{c}5.21 \\
(1.00)\end{array}$ & 0.83 & 0.63 & 0.3 & & $\begin{array}{c}5.21 \\
(1.00)\end{array}$ & 0.84 & 0.64 & 0.3 \\
\hline $\begin{array}{l}\text { It is simple for me to change the } \\
\text { availability of my services/goods. }\end{array}$ & $0.93^{\star \star \star}$ & $\begin{array}{c}5.03 \\
(1.00)\end{array}$ & & & & $0.90^{\star \star \star}$ & $\begin{array}{c}5.03 \\
(1.00)\end{array}$ & & & \\
\hline $\begin{array}{l}\text { I should be able to accept or deny } \\
\text { someone's offer. }\end{array}$ & $0.56^{*}$ & $\begin{array}{c}5.36 \\
(1.03)\end{array}$ & & & & $0.65^{\star \star \star}$ & $\begin{array}{c}5.36 \\
(1.03)\end{array}$ & & & \\
\hline $\begin{array}{l}\text { I can change when and for how long I } \\
\text { offer my services/goods. }\end{array}$ & $0.84^{\star \star \star}$ & $\begin{array}{c}5.24 \\
(0.95)\end{array}$ & & & & $0.83^{\star \star \star}$ & $\begin{array}{c}5.24 \\
(0.95)\end{array}$ & & & \\
\hline Trust & & $\begin{array}{c}5.24 \\
(0.96) \\
\end{array}$ & 0.84 & 0.73 & 0.12 & & $\begin{array}{c}5.13 \\
(1.03) \\
\end{array}$ & 0.82 & 0.6 & 0.25 \\
\hline $\begin{array}{l}\text { I am comfortable with providing services } \\
\text { because the platform ensures a robust } \\
\text { and safe environment. }\end{array}$ & $0.86^{* *}$ & $\begin{array}{c}5.18 \\
(1.00)\end{array}$ & & & & $0.73^{* *}$ & $\begin{array}{c}5.18 \\
(1.00)\end{array}$ & & & \\
\hline $\begin{array}{l}\text { The platform will protect me from liability } \\
\text { and interests of others that do not match } \\
\text { with mine. }\end{array}$ & & & & & & $0.66^{*}$ & $\begin{array}{c}4.91 \\
(1.17)\end{array}$ & & & \\
\hline $\begin{array}{l}\text { I trust that the platform shows me } \\
\text { accurate updates and information. }\end{array}$ & $0.84^{* *}$ & $\begin{array}{c}5.29 \\
(0.92) \\
\end{array}$ & & & & $0.91^{\star \star \star}$ & $\begin{array}{c}5.29 \\
(0.92) \\
\end{array}$ & & & \\
\hline Convenience & & $\begin{array}{c}5.29 \\
(0.93)\end{array}$ & 0.82 & 0.61 & 0.23 & & $\begin{array}{c}5.29 \\
(0.93)\end{array}$ & 0.83 & 0.62 & 0.27 \\
\hline $\begin{array}{l}\text { The platform makes it easy to complete a } \\
\text { transaction. }\end{array}$ & $0.64^{*}$ & $\begin{array}{c}5.24 \\
(0.93)\end{array}$ & & & & $0.62^{\star \star}$ & $\begin{array}{c}5.24 \\
(0.93)\end{array}$ & & & \\
\hline $\begin{array}{l}\text { The platform offers quick and easy } \\
\text { access to the information I need. }\end{array}$ & $0.75^{\star \star}$ & $\begin{array}{c}5.22 \\
(0.93)\end{array}$ & & & & $0.84^{\star \star \star}$ & $\begin{array}{c}5.22 \\
(0.93)\end{array}$ & & & \\
\hline $\begin{array}{l}\text { The platform is easy to use and self- } \\
\text { explanatory. }\end{array}$ & $0.91^{* *}$ & $\begin{array}{c}5.05 \\
(0.95)\end{array}$ & & & & $0.88^{\star \star \star}$ & $\begin{array}{c}5.05 \\
(0.95)\end{array}$ & & & \\
\hline Sense of Belonging & & $\begin{array}{c}3.38 \\
(1.45)\end{array}$ & 0.87 & 0.7 & 0.38 & & $\begin{array}{c}3.38 \\
(1.45)\end{array}$ & 0.86 & 0.68 & 0.37 \\
\hline $\begin{array}{l}\text { I want to feel part of a bigger community } \\
\text { of like-minded people. }\end{array}$ & $0.87^{\star \star \star}$ & $\begin{array}{c}3.44 \\
(1.45)\end{array}$ & & & & $0.93^{\star \star \star}$ & $\begin{array}{c}3.44 \\
(1.45)\end{array}$ & & & \\
\hline $\begin{array}{l}\text { The use of the platform allows me to } \\
\text { belong to a group of people with similar } \\
\text { interests. }\end{array}$ & $0.87^{\star \star \star}$ & $\begin{array}{c}3.19 \\
(1.47)\end{array}$ & & & & $0.87^{\star \star \star}$ & $\begin{array}{c}3.19 \\
(1.47)\end{array}$ & & & \\
\hline $\begin{array}{l}\text { The platform reflects my culture, values } \\
\text { and interests. }\end{array}$ & $0.76^{* \star *}$ & $\begin{array}{c}3.51 \\
(1.42)\end{array}$ & & & & $0.65^{\star \star *}$ & $\begin{array}{c}3.51 \\
(1.42)\end{array}$ & & & \\
\hline Willingness to Provide Goods & & $\begin{array}{c}3.91 \\
(1.37) \\
\end{array}$ & 0.87 & 0.77 & 0.28 & & & & & \\
\hline $\begin{array}{l}\text { I am interested in providing sharing } \\
\text { economy goods (e.g. sharing my house } \\
\text { in Airbnb, renting my bike in Spinlister). }\end{array}$ & $0.89^{* * *}$ & $\begin{array}{c}3.66 \\
(1.40)\end{array}$ & & & & & & & & \\
\hline $\begin{array}{l}\text { I prefer to share my idle goods instead of } \\
\text { having them unused. }\end{array}$ & $0.85^{\star \star \star}$ & $\begin{array}{c}4.15 \\
(1.34) \\
\end{array}$ & & & & & & & & \\
\hline
\end{tabular}




\section{Willingness to Provide Services}

I am interested in providing sharing economy services (e.g. driving my car for Uber, taking care of someone else's pet while they're away in DogVacay, offering my services and skills in TaskRabbit).
3.83

(1.43)

${ }^{*} p<0.05,{ }^{* *} p<0.10,{ }^{* *} p<0.001$

to notice that because of the predictive purpose of this PLS-SEM study, low values for $R^{2}$ can be accepted [19]. Finally, the Stone-Geisser's $Q^{2}$ value should be larger than zero and it shows the cross-validated predictive relevance of the model [4] and is obtained by using the "blindfolding" technique with omission distance of 6 .

In order to improve the accuracy and reliability of results, PLS-SEM allows the deletion of reflective indicators, as these indicators are interchangeable. When outer loadings values are less than 0.5, then the indicator can be omitted [3], [4], [28]. In our goods model, only one variable for trust ("liability protection") was a candidate for deletion with an outer loading of -0.318. In our adapted model, all outer loadings have a value over 0.5 so no more changes were needed.

For both models (see Table 4) all values for CR and AVE surpass the cut-off values. All values for CR are above 0.8 , the satisfactory result for advanced levels of research. It must be pointed out that both the $\mathrm{CR}$ and AVE value for the variable "Willingness" for the services model are both 1.00 due to the fact that the variable only has one indicator, in contrast to all the other variables in both models.

\section{Findings}

Table 5 shows the results for both PLS-SEM models.
P-values are obtained by bootstrapping with 10000 iterations, which is above the recommended 5000 [4].

\subsection{Willingness to provide goods model}

The analysis results show that three out of the five determinants (i.e., flexibility, trust and convenience) do not have a significant positive effect on willingness to provide goods, thus hypotheses, $\mathrm{H}_{2 \mathrm{a}}, \mathrm{H}_{3 \mathrm{a}}$ and $\mathrm{H}_{4 \mathrm{a}}$ respectively, are not supported and rejected (refer to Table 5). Even though significant, the path coefficient for $\mathrm{H}_{1 \mathrm{a}}$ is negative and hence it does not prove a positive effect on the variable willingness to provide goods, but rather a negative one, thus hypothesis $\mathrm{H}_{1 \mathrm{a}}$ is rejected.

The determinant sense of belonging (i.e., hypothesis $\mathrm{H}_{5 \mathrm{a}}$ ) has enough evidence to be supported with a positive and significant path coefficient.

\subsection{Willingness to provide services model}

Only the hypothesis related to sense of belonging (i.e., $\mathrm{H}_{5 \mathrm{~b}}$ ) has been supported for the model with a significant positive path coefficient. No other determinants have a significant correlation from the analysis and so hypotheses $\mathrm{H}_{1 \mathrm{~b}}$ (i.e. monetary compensation), $\mathrm{H}_{2 b}$ (i.e. flexibility), $\mathrm{H}_{3 b}$ (i.e. trust), and $\mathrm{H}_{4 \mathrm{~b}}$ (i.e. convenience) are rejected (refer to Table 5).

Table 5. Results per model

\begin{tabular}{|c|c|c|c|c|}
\hline \multirow[b]{2}{*}{ Hypothesis } & \multicolumn{2}{|c|}{ Goods } & \multicolumn{2}{|c|}{ Services } \\
\hline & $\begin{array}{c}\text { Path } \\
\text { Coefficient }\end{array}$ & Support & $\begin{array}{c}\text { Path } \\
\text { Coefficient }\end{array}$ & Support \\
\hline $\mathrm{H}_{1 \mathrm{a}}$ : Monetary compensation $\rightarrow$ Willingness to provide goods & $-0.205^{*}$ & No & & \\
\hline $\mathrm{H}_{1 \mathrm{~b}}$ : Monetary compensation $\rightarrow$ Willingness to provide services & & & 0.037 & No \\
\hline $\mathrm{H}_{2 \mathrm{a}}$ : Flexibility $\rightarrow$ Willingness to provide goods & 0.137 & No & & \\
\hline $\mathrm{H}_{2 \mathrm{~b}}$ : Flexibility $\rightarrow$ Willingness to provide services & & & 0.126 & No \\
\hline $\mathrm{H}_{3 a}:$ Trust $\rightarrow$ Willingness to provide goods & 0.056 & No & & \\
\hline $\mathrm{H}_{3 b}:$ Trust $\rightarrow$ Willingness to provide services & & & 0.100 & No \\
\hline $\mathrm{H}_{4 \mathrm{a}}$ : Convenience $\rightarrow$ Willingness to provide goods & -0.012 & No & & \\
\hline $\mathrm{H}_{4 \mathrm{~b}}$ : Convenience $\rightarrow$ Willingness to provide services & & & -0.018 & No \\
\hline $\mathrm{H}_{5 a}$ : Sense of belonging $\rightarrow$ Willingness to provide goods & $0.207^{\star \star}$ & Yes & & \\
\hline $\mathrm{H}_{5 b}$ : Sense of belonging $\rightarrow$ Willingness to provide services & & & $0.206^{* *}$ & Yes \\
\hline
\end{tabular}

${ }^{*} p<0.05,{ }^{* *} p<0.10,{ }^{* *} p<0.001$ 


\section{Discussion}

For both models, only sense of belonging seems to have a positive significant effect on willingness to provide. As suggested by [1], the illusion of connecting with others, even if superficially, through sharing seems to make "sense of belonging" the main driver for participation. Through this study, we show that the same holds true for providers as well, and not only for users. With an increase in capitalism and an individual focus, it would not be surprising that people are looking for a connection with others through other non-conventional means.

One way to explain why sense of belonging stands out from the other chosen determinants is the influence of culture. One of the statements given to participants was "The platform reflects my culture, values and interests" which had a mean (3.51) greater than the other two indicators for the same variable (3.44 and 3.19). The information obtained from the study shows that culture plays an important role in someone's motivation to participate as a provider.

Another finding of interest is that of the determinant "monetary compensation". Besides the determinant "sense of belonging", monetary compensation is the only other significant determinant that has a significant p-value. $\mathrm{H}_{1 \mathrm{a}}$ is rejected as the result indicates a negative effect on willingness to provide goods, which is surprising as the literature indicated a positive effect.

As a striking result, it gives interesting information regarding the motives to provide in the sharing economy, at least for goods. The results indicate that the stronger someone's emphasis on monetary compensation is, the smaller their willingness to provide goods is. Instead, as indicated by the significant positive effect on sense of belonging, the incentive of being part of a community of like-minded people and the possibility to network is more effective.

It is fascinating to notice that in general people do care about monetary compensation, as seen with its mean of 5.200 (refer to Table 4). However, people who seemed to care more about money were not as willing to become providers in the goods market. People who are truly inspired to share are those who are looking for a satisfactory experience with a group of people with similar culture, values and interests. Earning money is not the only factor that is important anymore. When compared to other determinants, sense of belonging is the only one that will motivate people to act as providers in the sharing economy. As previously mentioned, this could be a side effect of an increasing pressure from capitalism and individualist behavior, which encourages a more self-centered focus on work and personal growth, so people end up looking for a connection through sharing as providers in the sharing economy.
The findings may be used by companies in advertising and marketing campaigns, as well as in the design of the online platform, to increase their number of providers. People want to feel part of a group of likeminded people. Part of a bigger community where they have the possibility to network and connect. If companies can put a greater emphasis on how the company shares the same values as their target group, or even how they can all be part of the same culture, people might be more interested in participating as providers.

These results are not only relevant when companies want to attract new providers, but also to motivate the ones who have already participated to keep doing so. If people who have provided before are kept content, platforms will have a stable source of goods and services in the long term that will only keep increasing in size and variety with the new providers.

Successful sharing economy platforms such as Airbnb are already implementing these techniques, which may help explain their success. Advertising for Airbnb has had a major focus on sense of belonging, especially for users, which has led to a stable demand. Airbnb's vision is a world where "Anyone Can Belong Anywhere" [37] and has been a major part of its advertising strategy and it is the main image people get from the company. The ability of making people feel as part of a community and integrate them into a foreign society and culture became a game-changer in the accommodation industry and has helped the company grow into what it is today. Other companies could see Airbnb as a successful example of a company that uses the incentive of sense of belonging to their advantage to keep growing in both number of providers and users.

\section{Conclusion}

The main aim of this paper was to analyse the motives to provide goods and services in the sharing economy. To understand the previous studies and the current literature on the topic, a thorough literature review was done where previous identified motives for both users and providers were described. Accordingly, five determinants (i.e., monetary compensation, flexibility, trust, convenience and sense of belonging) were selected for the conceptual framework.

A survey was conducted and the gathered data analysed using PLS-SEM. The results show two significant determinants for incentivizing providers to lend their goods: sense of belonging and monetary compensation. While sense of belonging has a positive effect on willingness to provide goods, monetary compensation has a negative effect. The latter surprising result has not been considered by any previous study before. As for the model considering the incentives to provide services in the sharing economy, sense of 
belonging is the only significant determinant with a positive effect on willingness to provide services. This shows providers' interest in being part of a community, a group of like-minded people, above any of the other chosen determinants.

This study contributes to the scarce literature on providers in the sharing economy by introducing a different perspective on their possible motives to share goods and services. Sense of belonging, a determinant that has only been studied in regard to users, is the only determinant found to have a significant positive effect on willingness to provide for both models. Further, monetary compensation, a determinant that was believed to be one of the main, or sole, incentive to become a provider [39] was shown to have a significant negative effect on willingness to provide goods.

The main limitations of our study include the inability to identify specific goods or services that current and possible providers are interested in. The statements used for the survey were not industryspecific, with the aim to have results that could be generalized. Moreover, $80 \%$ of the participants belonged to the age group of 18-24 years of age and 35\% of the total sample have a monthly income of 300 euros or less. This may suggest that there is a large percentage of students who took part on the survey which may affect the generalization of results. Also, the $R^{2}$ of both models was relatively low, below $15 \%$. Further studies can focus on trying to increase this value in order to explain a greater percentage of the variability that may come with the study.

Even though this paper has provided valuable insights on the existing research gap, more research should be done on the topic in order to validate and build upon the results. Choosing an industry (e.g., ridesharing, hospitality industry) could help get more specific results instead of the general ones presented in this study. Besides, further research on age-groups, country of residence and monthly income could generate more results that would help both the academic community and companies understand what motivates people to become providers according to the target group they wish to incentivize. Further research can also investigate why monetary compensation has a negative effect on the willingness to provide goods on the contrary to what has been suggested in previous literature. Also, only two determinants were found to be significant. Extra work on other determinants would also be beneficial to the current research gap.

The main driver to participate as a provider in the sharing economy is sense of belonging. Knowing this, both start-ups and established companies in the sharing economy market can create new advertising and marketing campaigns that emphasize this motive. Creating networking options and redesigning the platforms in a way that makes providers feel a part of a community may not only increase the number regarding the participation of providers, but also aid in increasing the satisfaction levels and keeping the providers they already have. This, in turn, will help keep old providers while attracting new ones.

The ability to have, share and give does not only help connect people; but, nowadays, it is the means for a greater sense of belonging. Connection is valued higher than money and it is through sharing and giving that people relate and work together.

\section{References}

[1] Albinsson, P. A., \& Yasanthi Perera, B. (2012). Alternative marketplaces in the 21st century: Building community through sharing events. Journal of consumer Behaviour, 11(4), 303-315.

[2] Albinsson, P. A., \& Yasanthi Perera, B. (Eds.). (2018). The rise of the sharing economy: Exploring the challenges and opportunities of collaborative consumption. ABC-CLIO.

[3] Avkiran, N. K. (Director). (2015, September 9). PLS SEM in SmartPLS software [Video file]. Retrieved May 7, 2019, from https://www.youtube.com/watch?v=SzQ_LJWnqgQ

[4] Avkiran, N. K. (2018). Explaining Systemic Risk in Money Market Funds. Theoretical Economics Letters, 8, 1525-1552. doi:https://doi.org/10.4236/tel.2018.89098

[5] Belk, R. (2009). Sharing. Journal of consumer research, 36(5), 715-734.

[6] Belk, R. (2014). You are what you can access: Sharing and collaborative consumption online. Journal of business research, 67(8), 1595-1600.

[7] Benoit, S., Baker, T. L., Bolton, R. N., Gruber, T., \& Kandampully, J. (2017). A triadic framework for collaborative consumption (CC): Motives, activities and resources \& capabilities of actors. Journal of Business Research, 79, 219227.

[8] Bezhanidze, T. (2018). Why do we share? A survey investigation of the motives to use and provide sharing economy services (Unpublished bachelors thesis). Jacobs University Bremen.

[9] Botsman, R. (2015). The sharing economy: Dictionary of commonly used terms. Collaborative Consumption, 12 .

[10] Brace, I. (2008). Questionnaire Design 2nd ed., London, Philadelphia: Kogan Page.

[11] Business Dictionary, goods. BusinessDictionary.com. Available http://www.businessdictionary.com/definition/goods.html [Accessed May 7, 2019].

[12] Chen, M.K. et al. (2017). The Value of Flexible Work: Evidence from Uber Drivers. NBER Working Paper Series. Available at: https://www.nber.org/papers/w23296.pdf.

[13] Cohen, B., \& Munoz, P. (2016). Sharing cities and sustainable consumption and production: towards an integrated framework. Journal of cleaner production, 134, 87- 
97.

[14] Davidson, A., Habibi, M. R., \& Laroche, M. (2018). Materialism and the sharing economy: A cross-cultural study of American and Indian consumers. Journal of Business Research, 82, 364-372.

[15] Falk, R.F. \& Miller, N.B. (1992). A Primer of Soft Modeling. University of Akron Press, Akron, $\mathrm{OH}$.

[16] Furuhata, M., Dessouky, M., Ordóñez, F., Brunet, M. E., Wang, X., \& Koenig, S. (2013). Ridesharing: The state-of-theart and future directions. Transportation Research Part B: Methodological, 57, 28-46.

[17] Gleim, M. R., Johnson, C. M., \& Lawson, S. J. (2019). Sharers and sellers: A multi-group examination of gig economy workers' perceptions. Journal of Business Research, 98, 142-152.

[18] Gupta, M., Esmaeilzadeh, P., Uz, I., \& Tennant, V. M. (2019). The effects of national cultural values on individuals' intention to participate in peer-to-peer sharing economy. Journal of Business Research, 97, 20-29.

[19] Hair, J. F., Jr., Ringle, C. M., \& Sarstedt, M. (2013). Partial Least Squares Structural Equation Modeling: Rigorous Applications, Better Results and Higher Acceptance. Long Range Planning, 46, 1-12. Retrieved May 7, 2019.

[20] Hair, J.F. et al., 2017. A Primer on Partial Least Squares Structural Equation Modeling (PLS-SEM) 2nd ed., Los Angeles, California: SAGE Publications, Inc.

[21] Hamari, J., Sjöklint, M., \& Ukkonen, A. (2016). The sharing economy: Why people participate in collaborative consumption. Journal of the association for information science and technology, 67(9), 2047-2059.

[22] Henseler, J., Hubona, G. \& Ray, P.A. (2017). Partial Least Squares Path Modeling: Updated Guidelines. Advances in International Marketing, 20, pp.277-319.

[23] Hooper, D., Coughlan, J., \& Mullen, M. R. (2008). Structural Equation Modelling: Guidelines for Determining Model Fit. Electronic Journal of Business Research Methods, 6(1), 53-60.

[24] Hu, L., \& Bentler, P. M. (1998). Fit Indices in Covariance Structure Modeling: Sensitivity to Underparameterized Model Misspecification. Psychological Methods, 3(4), 424-453.

[25] Jackson, R. W., Neidell, L. A., \& Lunsford, D. A. (1995). An empirical investigation of the differences in goods and services as perceived by organizational buyers. Industrial Marketing Management, 24(2), 99-108.

[26] Ke, Q. (2017). Service providers of the sharing economy: who joins and who benefits? Proceedings of the ACM on Human-Computer Interaction, 1(CSCW), 57. pp.117. doi.org/10.1145/3134692

[27] Key, T. M. (2017). Domains of digital marketing channels in the sharing economy. Journal of Marketing Channels, 24(1-2), 27-38.

[28] King, C., \& Grace, D. (2010). Building and measuring employee-based brand equity. European Journal of Marketing, 44(7/8), 938-971. doi:https://doi.org/10.1108/03090561011047472

[29] Kumar, V., Lahiri, A., \& Dogan, O. B. (2018). A strategic framework for a profitable business model in the sharing economy. Industrial Marketing Management, 69, 147-160.

[30] Lee, Z. W., Chan, T. K., Balaji, M. S., \& Chong, A. Y. L. (2018). Why people participate in the sharing economy: an empirical investigation of Uber. Internet Research, 28(3), 829-850. Available at: doi.org/10.1108/IntR-01-2017-0037.

[31] Lindblom, A., Lindblom, T., \& Wechtler, H. (2018). Collaborative consumption as $\mathrm{C} 2 \mathrm{C}$ trading: Analyzing the effects of materialism and price consciousness. Journal of Retailing and Consumer Services, 44, 244-252.

[32] Luca, M. (2017). Designing online marketplaces: Trust and reputation mechanisms. Innovation Policy and the Economy, 17(1), 77-93.

[33] Lutz, C., \& Newlands, G. (2018). Consumer segmentation within the sharing economy: The case of Airbnb. Journal of Business Research, 88, 187-196.

[34] Möhlmann, M. (2015). Collaborative consumption: determinants of satisfaction and the likelihood of using a sharing economy option again. Journal of Consumer Behaviour, 14(3), 193-207.

[35] Nau, R. (n.d.). What's a good value for R-Squared? Duke University, Retrieved May 7, 2019, from https://people.duke.edu/ rnau/rsquared.htm

[36] Owyang, J. (2014). Framework: Collaborative Economy Honeycomb. Web Strategy by Jeremiah Owyang Digital Business Framework Collaborative Economy Honeycomb Comments. Available at: http://www.webstrategist.com/blog/2014/05/05/framework-collaborativeeconomy-honeycomb-osfest14/ [Accessed November 6, 2018].

[37] Passiak, D. (2017). Belong Anywhere - The Vision and Story Behind Airbnb's Global Community. Medium. Available at: https://medium.com/cocreatethefuture/belonganywhere-the-vision-and-story-behind-airbnbs-globalcommunity-123d32218d6a [Accessed May 11, 2019].

[38] Rougès, J. F., \& Montreuil, B. (2014). Crowdsourcing delivery: New interconnected business models to reinvent delivery. In 1st international physical internet conference (pp. 1-19).

[39] Teodoro, R., Ozturk, P., Naaman, M., Mason, W., \& Lindqvist, J. (2014, February). The motivations and experiences of the on-demand mobile workforce. In Proceedings of the 17th ACM conference on Computer supported cooperative work \& social computing (pp. 236247). ACM.

[40] The Economist. (2013). The rise of the sharing economy. The Economist. Available at: https://www.economist.com/leaders/2013/03/09/the-rise-ofthe-sharing-economy [Accessed November 21, 2018].

[41] Wright, K. B. (2005). Researching Internet-based populations: Advantages and disadvantages of online survey research, online questionnaire authoring software packages, and web survey services. Journal of computer-mediated communication, 10(3), JCMC1034.

[42] Yaraghi, N., \& Ravi, S. (2017). The current and future state of the sharing economy. Available at SSRN 3041207.

[43] Deci, E. L., \& Ryan, R. M. (1985). Intrinsic motivation and self-determination in human behavior: Plenum, New York. 